\title{
Patientenrechtegesetz
}

\section{Wirklich ein Gesetz für die Patienten?}

\author{
Seit Kurzem liegt der Regierungsentwurf für ein einheitliches \\ Patientenrechtegesetz vor. Er bündelt die bisher über mehrere \\ Rechtsbereiche verteilten Schutzregelungen. Doch ist es der große \\ Wurf, der den Patienten mehr Schutz im komplizierter werdenden \\ Gesundheitssystem bieten wird? Große Hoffnung darf man sich wohl \\ nicht machen - denn der Entwurf fokussiert fast ausschließlich die \\ eigentlich gute Beziehung zwischen Patient und Arzt.
}

ange ist über den Entwurf zum Patientenrechtegesetz diskutiert und beraten worden. Viele Strategiepapiere von Bund und Ländern, Patientenvertretern und anderen Verbänden aus der Gesundheitsszene tanzten über das Berliner Parkett. Das Ergebnis der Diskussionen ist ein kaum 50 Seiten starker Gesetzesentwurf, der damit eher zu den kleineren seiner Art zählt. Aber in der Kürze liegt die Würze! Erst der Blick in den Gesetzestext zeigt, ob die Erwartungen getroffen wurden.

Patientenrechte findet man heute in einer Vielzahl von Vorschriften in verschiedenen Rechtsbereichen. Vieles ist bisher nur im sogenannten Richterrecht festgeschrieben, also in Gerichtsurteilen für die ein bestehendes Gesetz interpretiert wurde. Wesentliche Bereiche des Patientenrechts sind auch das Behandlung- und Arzthaftungsrecht. Für Patienten, aber gleichermaßen auch Ärzte, stellte diese Vielzahl an Quellen bisher einen fast undurchdringlichen Rechtsdschungel dar.

\section{Mehr Transparenz für Patienten}

Genau hier setzt das Patientenrechtegesetz an: Es sammelt die Vorschriften aus den verschiedenen Rechtsgebieten sowie das Richterrecht und kodifiziert sie einheitlich im Bürgerlichen Gesetzbuch (BGB) unter dem Stichwort „Behandlungsvertrag“. Dabei wird vieles festgelegt, was Patientenvertreter fordern: Informationsund Aufklärungspflichten der Ärzte, die Pflicht zur Dokumentation der Behandlung und - nicht unwesentlich - das
Akteneinsichtsrecht für den Patienten. Das schafft zunächst einmal mehr Transparenz für Patienten.

Die Regeln zur Beweislast bei Kunstfehlern in der ärztlichen Behandlung werden ebenfalls „neu“ formuliert. Nach der juristischen Faustregel „Jeder muss das beweisen, was für ihn günstig ist “ trägt der Patient im Falle eines Schadens die Beweislast. Bei groben Behandlungsfehlern - etwa das Zurücklassen von Fremdkörpern bei Operationen - sieht der Entwurf dahingegen eine Beweislastumkehr vor. In diesen Fällen ist es der Arzt, der beweisen muss, dass er keine Schuld an etwaigen Gesundheitsschäden trägt. Richtig neu ist das übrigens nicht, denn es entspricht der gängigen Rechtsprechung, ist also heute schon Teil des „Richterrechts“. Bei leichten Behandlungsfehlern muss auch in Zukunft immer noch der Patient nachweisen, dass der Schaden aufgrund eines Fehlverhaltens des Arztes eingetreten ist.

\section{Kassen sollen ihre Versicherten unterstützen}

Neu ist, dass die gesetzlichen Krankenkassen künftig verpflichtet sind, ihren Versicherten zu helfen, den Schadenersatzanspruch geltend $\mathrm{zu}$ machen. $\mathrm{Ob}$ eine Krankenkasse die erste Wahl als Sachverwalter der Patienteninteressen ist, wenn es darum geht, den Versicherten bei der Durchsetzung von Schadensersatzansprüchen zu unterstützen, kann man durchaus bezweifeln. So manche Kasse tut sich bekanntlich schwer, Versorgungsverantwortung zu übernehmen. Im Fokus stehen bei den „Kostenträgern“ allzu oft eher kurzfristige finanzielle Einsparungen - und nicht unbedingt die Patienteninteressen.

Neu ist des Weiteren, dass Patienten genehmigungspflichtige Behandlungen auch ohne Bescheid der Kasse beginnen dürfen, wenn diese nicht innerhalb von drei Wochen entschieden hat. Ein zeitnaher Therapieablauf dürfte damit gewährleistet werden.

\section{Kernproblem nicht berührt}

Die Kernproblematik des Patientenrechts geht der Entwurf jedoch nicht an. Der Berliner Kammerpräsident Dr. Günter Jonitz sagt es deutlich: „Der Patient muss nicht vor dem Arzt geschützt werden, sondern vor der Politik." Das Arzt-Patienten-Verhältnis ist grundsätzlich von Vertrauen geprägt - also ein funktionierendes Verhältnis. Es sind vielmehr politische Entscheidungen, die für einen ständig steigenden Sparzwang sorgen, die innerhalb der Versorgung Sektorengrenzen aufbauen und Wirtschaftlichkeit an vorderste Stelle stellen. All dies führt zu einer zunehmend mangelhaften Versorgung der Patienten.

Dem setzt der Entwurf nichts entgegen. Ärzte und Patienten bräuchten dringend wieder ausreichend Raum und Zeit für die individuelle Behandlung - hier müsste die Politik ansetzen. Jonitz bringt es auf den Punkt: „Was wäre den Passagieren auf der vor 100 Jahren gesunkenen ,Titanic lieber gewesen: Ein Passagierrechtegesetz oder ein besserer Kapitän?“

\section{Tjarko J. Schröder}

Gesundheitspolitik und Kommunikation Deutscher Hausärzteverband 